\title{
Frontline Employee Organizational Behavior based on street level bureaucracy reviews
}

\author{
Marianus Dabingaya \\ The University of Papua New Guinea, PNG
}

\begin{abstract}
This article discusses organizational behavior is the result of interactions between individuals in an organization. The reality of public administration in a 'street level' bureaucracy is that it cannot operate hierarchically because the agency has to rely on street-level bureaucrats to provide services. The orientation of street level bureaucracy towards regulations and procedures is very high and makes it a barometer of service which results in low ability of street level bureaucracy to respond to changes, lack of initiative and development of creativity in controlling change so that routine is considered something normal. Understanding human behavior is a difficult thing because every human being as an individual has different behavior. Street-level bureaucrats have so much discretion that the problem is found in a lack of accountability either to the wider community, to management, or to clients.
\end{abstract}

Keywords: Organization, Behavior, Employees

Received : August 17, 2020

Received in Revised: August 25, 2020

Accepted: August 28, 2020

\section{Background}

Organizational behavior is a study that concerns aspects of human behavior in a particular organization or group. The first aspect includes the influence of the organization on humans, while the second aspect includes the influence of humans on the organization. Organizational behavior includes interactions and relationships between organizations on the one hand and individual behavior on the other (Griffin et al., 2004). Organizational behavior means studying the behavior of the members of the organization as a whole will give color, characteristics and types of organizational situations, how the organization moves to achieve the goals set by the behavior of members of the organization, both individually and in groups.

Organizational behavior is the result of interactions between individuals in an organization. Organizational behavior is a field of study that investigates the influence that individuals, groups and structures have on behavior in organizations, which aims to apply this kind of knowledge in order to increase the effectiveness of a company (Schneider, 1982; Kickul et al., 2002).

Organizational behavior is a study that concerns aspects of human behavior in an organization or a particular group. According to the opinion of these experts, it can be concluded that organizational behavior is the behavior of an individual in a particular organization or group which aims to increase the effectiveness of a company.

Organizational behavior is a field of study that invests the influence of individuals, groups and structures on behavior within organizations for the purpose of applying knowledge to increase organizational effectiveness. Studying organizational behavior 
is not studying how the organization behaves, but studying learning how members of the organization behave means trying to understand human behavior. Understanding human behavior is a difficult thing because every human being as an individual has different behavior. Human behavior is influenced by various factors; among others, environmental factors.

\section{Human behavior is influenced by two factors}

Need to be considered in an organizational behavior is as follows the study of organizational behavior including the relevant parts of all behavioral sciences that attempt to explain human actions in the organization. Organizational behavior is as a discipline concerning that individuals are influenced by how work is organized and who is responsible for its implementation. Even though there are uniqueness of individuals known, organizational behavior still focuses on the needs of managers to ensure that the overall job duties can be carried out.

There are a number of reasons among experts, why organizational behavior is necessary. However, all the existing opinions show that there is an increasing attention to the interests of human resources as workers in the organization. If human resources are considered, in turn, it will contribute higher to the organization. Among other things, there are three reasons why it is necessary to study organizational behavior. (1) Practical Application In the real reality of an organization, there are several benefits to understanding organizational behavior, including with regard to developing leadership styles, choosing strategies to solve problems, selecting appropriate jobs, improving performance and so on. (2) Personal Growth Understanding organizational behavior can better understand other people. Understanding others will give you greater self-knowledge and self-insight. By understanding other people, superiors can assess what subordinates need to develop themselves so that in turn increases their contribution to the organization. (3) Increased knowledge Organizational behavior can incorporate knowledge about humans in employment. Organizational behavior studies can help people think about problems related to work experience. Critical thinking skills can be useful in analyzing both work and personal problems.

Behavior because it is related to the performance of human resources. The performance of human resources will be able to increase if their behavior is in accordance with the demands of the job. Therefore, it supports the need for Behavior Kinetics which is a scientific approach to behavior change because it can perform four important functions of science: describing, explaining, predicting, and controlling. In addition, organizational attention to human resources shows an increasing trend (Hupe \& Hill, 2007).

Workers are trusted, empowered and heard from their opinions. Such an organization is called a people-centered organization, which is indicated by the following characteristics: (1) Guaranteed job security so as to eliminate fear of dismissal. (2) Acceptance of human resources is carried out prudently, emphasizing compatibility with the organizational culture. (3) Power is increasingly being pushed to people at lower levels, through decentralization and self-managed teams. (4) Pay is based on performance, not just seniority. (5) Provide many training opportunities. Less emphasis on status, but build feelings. (7) build trust, through sharing important information. 
Feedback in communicating between officials or employees in a particular organization, effective or ineffective, here are some characteristics that can be used to identify it, including the following: Intention: Feedback is effective if directed directly to improve work execution and more make employees as the most valuable property of the organization. This kind of feedback is impersonal and should not compromise personal feelings, self-esteem and goals. Effective feedback only deals with or is only directed at aspects of the employee's job.

Specificity Effective feedback is designed to equip recipients with specific information so they know what to do in a situation that is right - ineffective feedback if it is general and leaves a mark on the recipient. Descriptive The effectiveness of feedback can also be done in a more descriptive way than that which is evaluative. This means that feedback should be avoided that is assessing or evaluating, but more emphasis should be placed on providing an explanation of the implementation of the work. Benefit of this Characteristic requires that each feedback contains information that employees can use to their superiors to improve and enhance their work.

Timely Feedback is effective when it comes to considerations that take into account the correct timing factor. There is a kind of rule, the sooner the feedback is given to subordinates, the faster the stimulus will be received by employees.

Readiness so that feedback can be effective, employees should have a readiness to receive this feedback. In this case, every information provision should be taken into account in advance, whether an employee is ready or not in receiving feedback. Clarity of feedback can be effective if it can be clearly understood by the recipient, a good way to know this is to prove it directly by asking the recipient to state the essence of the discussion that has been done. Validity so that a feedback can be effective, then the feedback should be reliable and valid (reliable and valid).

\section{Levels in Organizational Behavior}

Organizational Behavior explains the three levels of bureaucratic behavior, namely at the individual level, each event will be diagnosed based on individual behavior. As we have seen, everyone who joins an organization carries with him a personality, value system, and different attitudes between one individual and another. Some are positive and some are negative. All of these reactions are none other than because each individual has different personalities, perceptions, and attitudes of the same job to the same boss, it does not mean that group behavior is the same as a collection of individual behaviors. The reason is, each group has its own norms of behavior that they build together and are accepted by everyone or most of the group members. Therefore, the group's behavior will continue to be maintained - as their identity and socialized among them as long as the group still exists. On the other hand, they will reject the behavior of other groups, mainly in order to maintain and protect their existence. For example, proposals for mechanization or computerization of product manufacturing would probably solve the problem of poor product quality. However, this good effort does not necessarily have the support of all parties. For the quality control department, for example, they really support this computerization. Thus, it will make their job easier. However, for the group of factory workers, this proposal may not be taken for granted. The reason is because there is a tendency that mechanization / computerization will result in a reduction in the workforce. When this happens, it is usually the factory employees who are reduced first. Hence, mechanization is considered a threat to groups of factory workers. 
The organization is a collection of individuals, but as in group behavior, a collection of individual behaviors is not a reflection of organizational behavior. At this level, all events that occur in the organization will be analyzed in an organizational context. In this case, organizational dimensions, such as organizational structure, design, and culture, will be understood as determinants that influence individual and group behavior. Overall, this will affect organizational behavior. For example, if an organization is designed as a hierarchical and centralized organization, in terms of the flow of information, for example, it can be expected that information will flow from the top leadership to the lowest organizational level. As a result, decision making is very slow because everything has to be decided above. Likewise, because lower-level managers are never given the opportunity to participate in decision making, these lower-level managers never experience a learning process so that their capabilities are low. Another result, the level of participation, ownership, and contribution to the organization is also low.

Organizational External Environment In addition to the individual, group and organizational levels, the external environment of the organization is also an important variable in analyzing organizational behavior. This is because humans cannot live in an isolated environment. They must interact, both with others within the organization and with those outside the organization.

Therefore, the events in the organization are also influenced by several factors that come from outside the organization. In other words, external environmental factors are important variables that should not be ignored in understanding human behavior and organizational behavior. For example, the low productivity of an employee may not be solely because the employee does not like working, because the employee is having problems with other employees, or because of insufficient organizational facilities, but perhaps because the employee knows that a colleague from another company has a job. the same earns a higher income. Another example, high employee turnover can be interpreted differently when economic conditions are different. When the economy is booming, high turnover can mean that employees have many opportunities to work elsewhere. Conversely, when the economy is in decline, high turnover means that the organization cannot maintain production stability so that the number of employees is also affected. These examples show once again that the external environment of the organization can influence human behavior in the organization.

\section{Organizational Behavior Indicators}

Organizational behavior is very important in organizational activities because everyone has different behaviors, therefore in studying organizational behavior according to Newstrom et al (1993) in Organizational behavior: Human behavior at work suggests dimensions in organizational behavior, namely: (1) ) people form the internal social system of the organization, they consist of people and groups, both large and small groups. In addition there are groups that are more formal and formal. (2) structure, determines the official relationship of the people in the organization. Different jobs are required to perform all organizational activities, there are managers and employees. (3) Technology, provides the resources that people use to work and those resources influence tasks for which they can produce many things empty-handed. So they construct buildings, design, machines create work processes and assemble resources. (4) Environment, all organizations operate in an external 
environment, the organization does not stand alone. It is part of a larger system that contains many other elements, such as government, families and other organizations. All of these elements influence each other in a complex system that makes up the life of a group of people.

\section{Street-level bureaucracy}

Looking back on the past, there are theories that emerged in the 1980s, namely the street-level bureaucracy theory by Lipsky (1980) and the work of Frederick Mosher (1992). public service workers who interact directly with citizens in the course of their jobs, who have substantial discretion in the execution of their work, such as teacher, police officers, law enforcement personnel, social workers, judges, health workers and many other public employees whi grant access to government programs and provide services with them.

From the perspective of citizens, the role of street level bureaucracy is broad, namely as a government function and intensive. As a daily routine it requires them to interact with education, dispute resolution, and health services. As individuals, street level bureaucracy represents citizens' expectations for fair and effective treatment by the government even when they are positioned to clearly see the limitations of effective interventions and the constraints on response that have been generated (Evans \& Harris, 2004).

The solution is the emergence of a new professionalism in hopes of developing and maintaining a new 'street-level' bureaucracy that meets the expectations of both the needs of bureaucrats and clients. Lipsky points out that political and social change with a focus on human concerns needs to surface for the changes he suggests.

The reality of public administration in a 'street-level' bureaucracy is that it cannot operate hierarchically because the agency has to rely on street-level bureaucrats to provide services (Prottas, 1978; Keizer, 1999). As street level bureaucrats are forced to develop mechanisms for clients due to limited resources and working conditions, negative attitudes are developing. Lipsky proposed three areas of change for public administration that would allow street-Level bureaucrats to be more responsive and sympathetic to the individual support of society.

Lipsky (1980) argues that the practice of street level bureaucracy is a mechanism to overcome difficult situations, namely as an attempt to get out of a frustrating situation between the large demand for services and limited resources. Moreover, in reality, the demand for service improvements seems to never stop. Furthermore, Lipsky (1980) describes the strengths and weaknesses of street-level bureaucracy. Street level bureaucracy strength:

1. Street-level bureaucracy as direct service providers means that these bureaucrats provide direct services to their customers (the public).

2. As a bureaucrat who imposes sanctions and restricts people's lives in accordance with established policies or procedures. These bureaucrats direct people to act in the context of social life.

3. They determine citizens' eligibility for government benefits and sanctions. They supervise citizen services in receiving the program. Thus, street level bureaucracy implicitly mediates aspects of the constitutional relations of citizens. In short, they hold the key to the dimension of citizenship (Hudson, 1989). 
Recruitment of employees among the street level bureaucracy that prioritizes representatives of the social composition of the community around the bureaucracy, making the bureaucracy ignore system merit and objectivity based on standard qualifications that have been set in employee recruitment. Therefore, in recruiting members of the bureaucracy, the term son of the region often appears. Regional sons who represent do not necessarily have sufficient capacity to occupy a position in the public service. This can make the performance of the bureaucracy less than optimal or it can be said to be unprofessional.

The orientation of street level bureaucracy towards regulations and procedures is very high and makes it a barometer of service which results in low ability of street level bureaucracy in responding to changes, lack of initiative and creativity development in controlling change so that routine is considered something reasonable and correct Performance of street level bureaucracy is the instrument of authority. The power system that tends to be centralized and paternalistic has resulted in the performance of street bureaucracy levels being concentrated on superior officials. The interests of the rulers who tend to be central and displace public interests result in a crisis of trust in the public bureaucracy.

\section{Conclusion}

Problems at street-level bureaucracy occur in task implementation activities. Therefore, continuous handling is needed in order to improve effective organizational performance. The steps taken must also cover structural and individual aspects, institutionally and environmentally so that they can touch all lines that are directly in contact with the community. Organizational development through bureaucratic reform is not separated from the discussion considering that this is often used as a means of verbal delivery and political means are used.

\section{References}

Prottas, J. M. (1978). The power of the street-level bureaucrat in public service bureaucracies. Urban Affairs Quarterly, 13(3), 285-312.

Mosher, F. C. (1992). Public administration old and new: A letter from Frederick C. Mosher. Journal of Public Administration Research and Theory: J-PART, 2(2), 199-202.

Hudson, B. (1989). Michael Lipsky and street level bureaucracy: a neglected perspective. Disability and dependency, 41-52.

Michael, L. (1980). Street-level bureaucracy: Dilemmas of the individual in public services. New York: Russell Sage Foundation.

Newstrom, J. W., Davis, K., \& Pierce, J. L. (1993). Organizational behavior: Human behavior at work.

Griffin, R. W., O'Leary-Kelly, A., \& Pritchard, R. D. (2004). The dark side of organizational behavior (pp. 23-61). San Francisco, CA: Jossey-Bass.

Schneider, B. (1982). Interactional psychology and organizational behavior. Michigan State Univ East Lansing Dept of Psychology.

Kickul, J., Lester, S. W., \& Finkl, J. (2002). Promise breaking during radical organizational change: do justice interventions make a difference?. Journal of 
Organizational Behavior: The International Journal of Industrial, Occupational and Organizational Psychology and Behavior, 23(4), 469-488.

Evans, T., \& Harris, J. (2004). Street-level bureaucracy, social work and the (exaggerated) death of discretion. The British Journal of Social Work, 34(6), 871-895.

Keiser, L. R. (1999). State bureaucratic discretion and the administration of social welfare programs: The case of social security disability. Journal of Public Administration Research and Theory, 9(1), 87-106. 